The Chittagong Univ. J. Sci. 41(1) : 178-199, 2019

DOI: https://doi.org/10.3329/cujs.v41i1.51922

\title{
Patterns and Differentials of Onset of Menstruation among School Girls in Chittagong Metropolitan Area of Bangladesh
}

\author{
Md Abdul Karim* and Jesmin Akter \\ Department of Statistics, University of Chittagong, Chittagong - 4331, Bangladesh \\ *Corresponding author: makstatcu@yahoo.com
}

\begin{abstract}
Onset of menstruation is the biological and physical indicator, which is one of the important components of female reproductive characteristics. Considering its importance in the context of reproductive health and fertility, the aim of this study is to determine the mean age at menarche and also to investigate the patterns and differentials of such an important vital event of the randomly selected girls aged 915 years from the schools of Chittagong metropolitan area. The results of this study show that the overall mean menarcheal age of the selected girls is only $11.75 \pm 0.97$ years with significant variations by their background characteristics. The coefficient of variation $(8.3 \%)$ indicates that there exists extreme heterogeneity in menarcheal age of the respondents. Co-efficient of skewness $\left(\beta_{1}=0.15\right)$ and excess of kurtosis $\left(\gamma_{2}=0.35\right)$ reflect that the shape characteristics of age at menarche is positively skewed and leptokurtic. The mean age at menarche is computed as relatively low (11.37 years) among the respondents residing in the metropolitan areas. The mean age at menarche is found the highest (12.01 years) among the underweight and the lowest among overweight (11.43 years) girls. The results from the life table technique show that unexpectedly $1.2 \%$ girls likely to attain menarche only within age of 9.67 years. The value of spread ( $s=16$ months) shows extreme
\end{abstract}


heterogeneity in menarcheal age. The values of trimean of onset of menstruation for underweight, normal and overweight girls are found 11.83, 11.58 and 11.41 years respectively.

Keywords: Menarcheal age, early menarche, menstruation, risk of breast cancer, body mass index, survival analysis, life table.

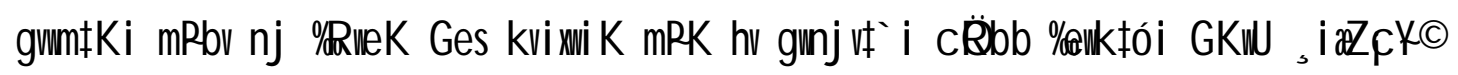

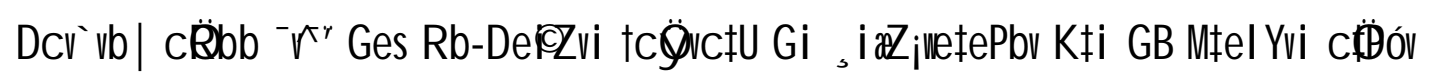

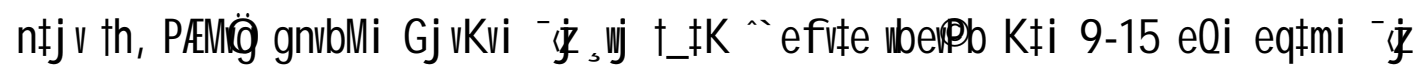

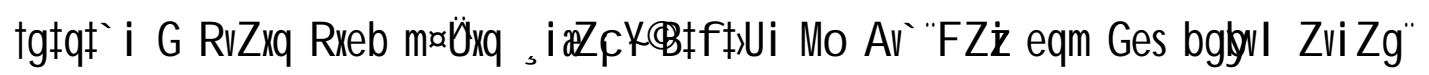

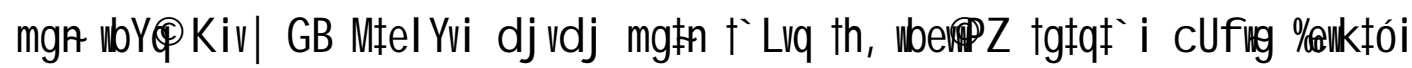

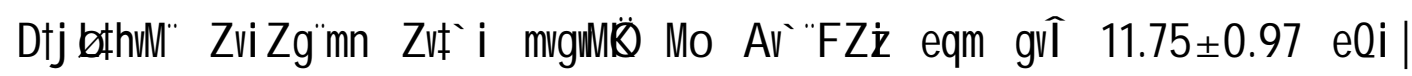

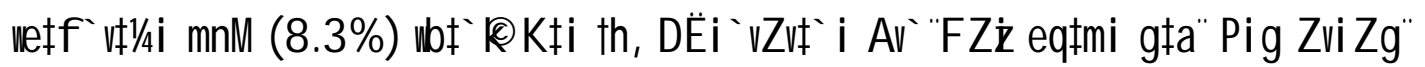

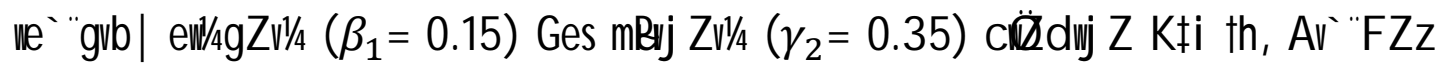

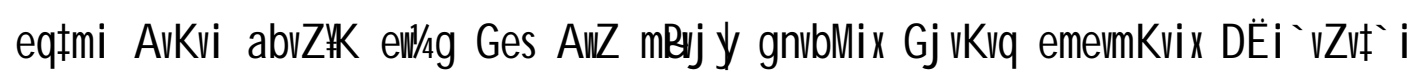

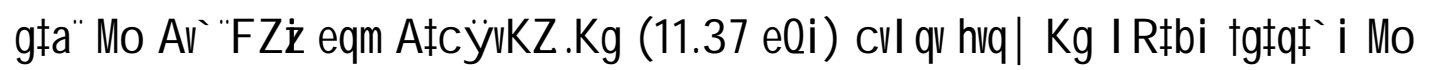

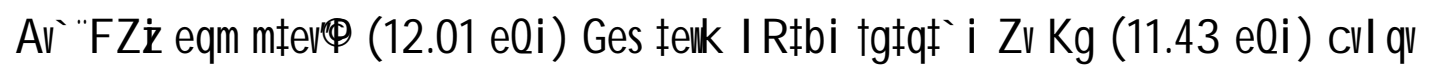

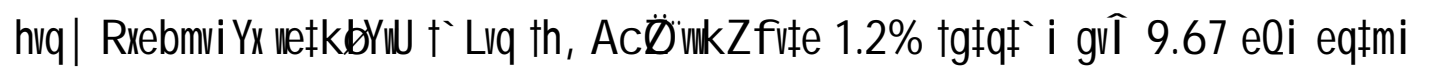

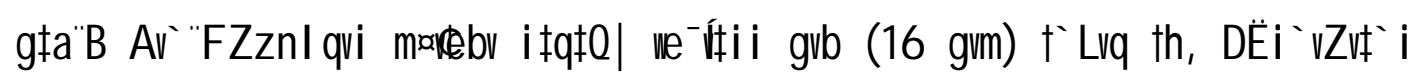

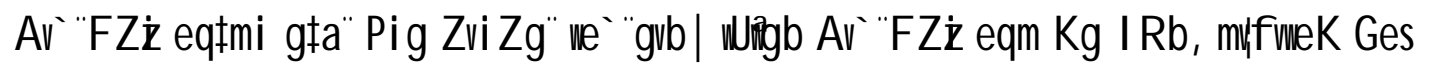
বেশি ওজনের মেয়েদের মধ্যে যথাক্রমে ১১.৮-৩, ১১.৫৮- Ges $1141 \mathrm{eQ}$ cV qvhq| 
180 Patterns and Differentials of Onset of Menstruation among School Girls in Chittagong Metropolitan Area of Bangladesh

\section{Introduction}

Menarche, a biological term is thought to signal the time when a female become capable of reproduction. This is one of the most important determinants of the reproductive system. Theoretically, timing of menarche of a girl is the time elapsed between the year of birth and year of attainment of puberty. In woman's life, menarche is considered as an important physiological episode. Menarche is recognized as one of the unique stages of the female reproductive life cycle along with sexual maturity [1]. There is overwhelming evidence of the declining age at which menarche occurs [2-4]. The timing of menarche is an important determinant of population size, reproductive performance and other chronic outcomes, like cancers in the reproductive organs [5]. Women who begin menstruating at an earlier age have more positive attitudes, less concerns about symptoms associated with menarche, and more ready acceptance than those who begin menstruating later $[6,7]$. The earlier onset of menarche is observed in groups with high living standards [8]. Early onset of menstruation ( $\leq 12$ years) is a well-established risk factor for breast cancer [9, 10], obesity [11, 12] and cardiovascular disease [13]. Early age at menarche is correlated with higher body mass index (BMI) than the average and later age at menarche [14, 15], premature marriage and early first motherhood, especially in developing countries $[5,16]$ and elevated adiposity in adolescence is predictive of elevated adiposity in adulthood [17]. Moreover, early menarche may be a risk factor for lower lung function and asthma in adulthood [18]. Late menarche may, however, be positively associated with the risk of developing Alzheimer's disease [19]. Early menarche is especially pronounced 
among students from urban environments and those with better educated mothers [20]. Menarche has an adverse effect on school attendance and natural activities of the girls because girls have no prior perception about this event. Moreover, fear, hesitation and lack of knowledge regarding pre-caution of this event. An increased age of marriage is correlated with the increased age at menarche [21]. There is a huge number of research works have been conducted in different dimensions among adolescent girls but elaborate and in-depth statistical studies about this important segment of reproductive span of school girls based on primary data have not been carried out in Bangladesh.

\section{Objectives of the Study}

The prime objective of this research work is to investigate extensively the timing of first menstruation among randomly selected school girls living in Chittagong metropolitan area. However, the specific objectives of this research study are as follows:

i) To compute the overall mean age at menarche of the selected girls;

ii) To examine the patterns and differentials of onset of menstruation;

iii) To estimate the proportions, trimean, quartiles and spread of onset of menstruation of the respondents along with other summary measures by employing life table technique and;

iv) To estimate the proportions, trimean, quartiles and spread of age at menarche by nutritional status (BMI) of the girls with other summary measures including those who have not attained menarche at the time of this survey.

\section{Materials and Methods}


Patterns and Differentials of Onset of Menstruation among School Girls in Chittagong Metropolitan Area of Bangladesh

\subsection{Target Area and Population}

Chittagong metropolitan area was chosen as the target area for this study.The rationale behind to select such an area because this region is a cosmopolitan in nature, the standard of living of this area is relatively high and urban facilities are also adequate because this city is a commercial capital of Bangladesh. Furthermore, girls living in this area are supposed to be relatively well-nourished and considerable number belongs to be overweight stratum, which is related to the onset of menstruation. Therefore, taking these into cognizance, the target population of this study is the school girls from class 5 to 10 and aged 9-15 years.

\subsection{Data Collection Procedure and Sample Size Determination}

This study was based on primary data which is an original, unique and first of its kind. The data was collected by personal interview method after pre-testing a schedule accordingly on the basis of 50 primarily selected school girls. As the population is finite, the following formula is used in determining sample size for estimating population mean age at menarche:

$$
\mathrm{n}=\frac{N z^{2} \sigma^{2}}{(N-1) d^{2}+z^{2} \sigma^{2}} ;
$$

The formula provides 925optimum sample size for this study with $\mathrm{N}=31350$ and $\hat{\sigma}^{2}=1.16$ (estimated from the primarily selected sample). For the determination of sample size, $99 \%$ confidence interval and $91 \%$ power were considered.

\subsection{Selection of Respondents and Data Analysis}

In this study, the list of schools in Chittagong metropolitan area was used as a sampling frame. Cluster sampling design was considered to select the respondents 
for conducting this study since the anthropometric and background characteristics of the respondents are heterogeneous. First of all, two schools were randomly selected out of 51 schools to make up the total sample size. The total number of female students aged 9-15 years in both the selected schools was 945. Thereafter, information was collected from 922 ultimate sampling units out of 945 because 23 respondents $(2.5 \%)$ were reluctant to enter into the interview.

\section{Methodology}

First of all, descriptive statistics are computed to compare the means, variability and shape characteristics of onset of menstruation by background characteristics of the respondents. Proportions of respondents by age at menarche are also computed and displayed to understand the patterns of onset of menstruation. Thereafter, life table analyses are also employed to estimate the proportions, trimean, quartiles and spread of menarcheal age of the respondents including the censored cases. The computational procedures of menarcheal age and exposure interval of this study are as follows:

Menarcheal age $=$ Date of onset of menstruation- Date of birth (Complete months)

Exposure interval $=$ Date of interview - Date of birth (Complete months)

\section{Results and Discussion}

Menarche usually occurs somewhere between the ages of 11 and 15 years with considerable variations in the mean age among different populations. Most of the girls are not aware about its sudden occurrence and consequences. Even that they have no preliminary idea about the specific age of first menstruation in advance. Therefore, it is an urgent need to investigate the age at menarche by different ages 
184 Patterns and Differentials of Onset of Menstruation among School Girls in Chittagong Metropolitan Area of Bangladesh

along with differentials by background characteristics for the awareness of the teenagers. In this context, percentage distribution of menarcheal girls in the different points of age is shown in the Table 1 and Fig. 1 for understanding about its occurrence.

Table 1. Percentage distribution of menarcheal age among girls.

\begin{tabular}{cc}
\hline $\begin{array}{c}\text { Menarcheal age } \\
\text { (years) }\end{array}$ & $\begin{array}{c}\text { Percentage } \\
(\boldsymbol{\%})\end{array}$ \\
\hline 8 & 0.3 \\
9 & 2.3 \\
10 & 16.9 \\
11 & 38.5 \\
12 & 32.2 \\
13 & 8.0 \\
14 & 1.8 \\
\hline
\end{tabular}

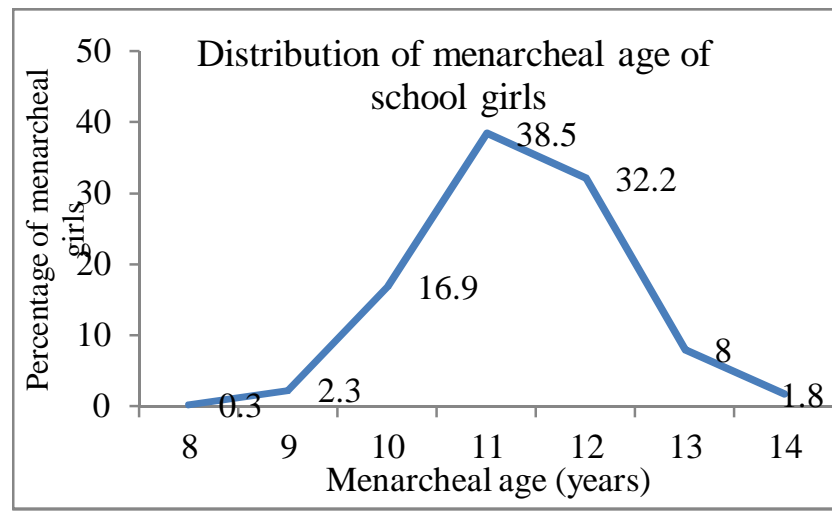

Fig. 1: Distribution of menarcheal age of the respondents by ages.

Fig. 1 along with Table 1 shows that majority of the respondent's attained menarche at 11 years with slight variations with neighboring ages. The differentials of age at menarche among the girls along with variability and shape characteristics for the same are also presented in the Table 2 .

Table 2. Summary measures of age at menarche by some selected background characteristics of school girls in Chittagong metropolitan area.

$\begin{array}{lll}\beta_{1} & \gamma_{2} & \text { No. of }\end{array}$




\begin{tabular}{|c|c|c|c|c|c|}
\hline Characteristics & menarche (years) & & & & respondents \\
\hline \multicolumn{6}{|c|}{ Respondent's current age (years) } \\
\hline $9-11$ & 10.84 & 0.59 & -0.16 & -0.70 & 82 \\
\hline $12-13$ & 11.66 & 0.83 & -0.34 & 0.22 & 464 \\
\hline $14-15$ & 12.25 & 1.05 & 0.04 & 0.26 & 228 \\
\hline \multicolumn{6}{|c|}{ Current place of residence } \\
\hline Semi-urban & 12.13 & 0.94 & 0.01 & 0.80 & 381 \\
\hline Urban & 11.37 & 0.84 & 0.08 & 0.17 & 393 \\
\hline \multicolumn{6}{|c|}{ Respondent's education (class) } \\
\hline 5 & 10.78 & 0.42 & 0.48 & 1.03 & 17 \\
\hline 6 to 8 & 11.67 & 0.92 & -0.03 & 0.16 & 611 \\
\hline 9 to 10 & 12.20 & 1.07 & 0.18 & 0.42 & 146 \\
\hline \multicolumn{6}{|l|}{ BMI } \\
\hline Underweight & 12.01 & 1.01 & 0.10 & 0.38 & 265 \\
\hline Normal & 11.67 & 0.88 & 0.04 & 0.41 & 391 \\
\hline Overweight & 11.43 & 1.01 & 0.37 & 0.29 & 118 \\
\hline \multicolumn{6}{|l|}{ Father's education } \\
\hline Below secondary & 11.88 & 1.22 & 0.01 & 0.14 & 68 \\
\hline Secondary & 12.01 & 0.99 & -0.16 & 1.14 & 128 \\
\hline Above secondary & 11.68 & 0.92 & 0.21 & 0.18 & 578 \\
\hline \multicolumn{6}{|l|}{ Mother's education } \\
\hline Below secondary & 11.99 & 1.23 & 0.17 & 0.46 & 82 \\
\hline Secondary & 11.95 & 1.03 & -0.10 & 0.38 & 175 \\
\hline Above secondary & 11.64 & 0.89 & 0.08 & -0.07 & 517 \\
\hline \multicolumn{6}{|l|}{ Father's Occupation } \\
\hline Business & 11.71 & 0.94 & 0.14 & 0.23 & 284 \\
\hline Service & 11.66 & 0.95 & 0.22 & 0.24 & 341 \\
\hline Others & 12.03 & 1.03 & -0.09 & 1.04 & 149 \\
\hline \multicolumn{6}{|c|}{ Mother's Occupation } \\
\hline House wife & 11.79 & 0.96 & 0.16 & 0.46 & 615 \\
\hline Service & 11.61 & 1.01 & 0.15 & 0.04 & 159 \\
\hline & & & & & Table 2 conti. \\
\hline $\begin{array}{c}\text { Background } \\
\text { Characteristics }\end{array}$ & $\begin{array}{c}\text { Mean Age at } \\
\text { menarche (years) }\end{array}$ & S. D. & $\beta_{1}$ & $\gamma_{2}$ & $\begin{array}{c}\text { No. of } \\
\text { respondents }\end{array}$ \\
\hline
\end{tabular}


186 Patterns and Differentials of Onset of Menstruation among School Girls in Chittagong Metropolitan Area of Bangladesh

\begin{tabular}{|c|c|c|c|c|c|}
\hline $\begin{array}{l}\text { Background } \\
\text { Characteristics }\end{array}$ & $\begin{array}{c}\text { Mean Age at } \\
\text { menarche (years) }\end{array}$ & S. D. & $\boldsymbol{\beta}_{1}$ & $\gamma_{2}$ & $\begin{array}{l}\text { No. of } \\
\text { respondents }\end{array}$ \\
\hline \multicolumn{6}{|c|}{ Socio-economic status } \\
\hline Low & 12.12 & 1.17 & 0.18 & -0.25 & 41 \\
\hline Middle & 11.78 & 0.96 & 0.08 & 0.42 & 622 \\
\hline High & 11.40 & 0.83 & 0.07 & -0.19 & 111 \\
\hline \multicolumn{6}{|c|}{ Family size (member) } \\
\hline$\leq 4$ & 11.67 & 0.94 & 0.14 & 0.14 & 300 \\
\hline 5 & 11.79 & 0.91 & 0.21 & 0.20 & 258 \\
\hline Above 5 & 11.81 & 1.08 & 0.09 & 0.51 & 216 \\
\hline \multicolumn{6}{|l|}{ Game } \\
\hline No & 11.66 & 1.07 & -0.08 & -0.15 & 123 \\
\hline Yes & 11.77 & 0.95 & 0.23 & 0.46 & 651 \\
\hline \multicolumn{6}{|c|}{ Sleeping per day (hours) } \\
\hline$\leq 6$ & 11.84 & 1.15 & 0.33 & 0.05 & 181 \\
\hline 7 to 8 & 11.75 & 0.85 & -0.03 & 0.26 & 380 \\
\hline Above 8 & 11.68 & 1.00 & 0.04 & 0.12 & 213 \\
\hline \multicolumn{6}{|l|}{ Food intake } \\
\hline Low \& normal & 11.94 & 0.94 & 0.19 & 0.68 & 516 \\
\hline Rich & 11.38 & 0.92 & 0.09 & -0.34 & 258 \\
\hline Overall & 11.75 & 0.97 & 0.15 & 0.35 & 774 \\
\hline C.V. (\%) & \multicolumn{5}{|c|}{8.3} \\
\hline
\end{tabular}

It has been observed from the Table 2 that the overall mean menarcheal age of the selected girls is found 11.75 years. The level of mean menarcheal age reflects that it is quite low among school girls in Chittagong metropolitan area. The co-efficient of variation $(\mathrm{C} . \mathrm{V})$, co-efficient of skewness $\left(\beta_{1}\right)$ and excess of kurtosis $\left(\gamma_{2}\right)$ of the ageat menarche are found $8.3 \%, 0.15$ and 0.35 respectively. The results reflect that the age at first menstruation is extremely heterogeneous and the shape characteristics are slightly positively skewed and leptokurtic. Findings of the menarcheal age in the Table 2 show that the lowest current age cohort has the lowest age for attaining menarche. In addition to differentials of age at menarche by 
current age, the patterns of mean age at menarche by current age cohorts are also portrayed in the Fig. 2 along with values in the Table 3.

Table 3. Observed mean menarcheal age of the respondents by their age cohort (years).

\begin{tabular}{cc}
\hline $\begin{array}{c}\text { Respondents } \\
\text { current age (years) }\end{array}$ & $\begin{array}{c}\text { Mean menarcheal } \\
\text { age (years) }\end{array}$ \\
\hline 10 & 10.4 \\
11 & 10.9 \\
12 & 11.4 \\
13 & 11.9 \\
14 & 12.1 \\
15 & 12.6 \\
\hline
\end{tabular}

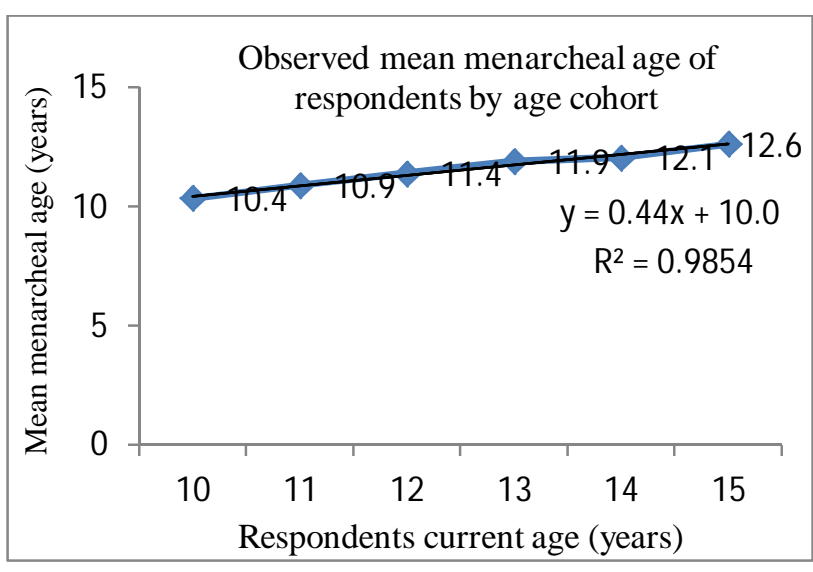

Fig. 2: Observed mean age at menarche of the respondents by their age cohort (years).

Fig. 2 at a glance shows that the pattern of age at menarche is narrowly increases by age cohort and the estimated rate of increment is 0.44 year $\left(\hat{\beta}_{\mathrm{yx}}=0.44\right)$. The mean menarcheal age is found relatively low among the respondents living in urban (11.37 years) areas. Surprisingly, the lowest mean menarcheal age is computed as only 10.78 years among the girls who read in class 5 , which is generally not normal. The early biological maturation of this cohort is associated with fear, hesitation, school absenteeism, early marriage, early first motherhood and overweight.

Findings of the Table 2 show that the mean age at menarche is lower (11.43 years) among the overweight girls compared to their underweight (12.01 years) counterparts. The mean menarcheal ages are computed as 11.88 and 12.01 years among the girls whose father's educational levels are below secondary and secondary 
188 Patterns and Differentials of Onset of Menstruation among School Girls in Chittagong Metropolitan Area of Bangladesh

respectively. The findings reveal that the mean menarcheal age of the girls is also found the lowest (11.64 years) whose mother's educational level is above secondary. The mean menarcheal age among the respondents is found the lowest (11.66 years) whose father's are service holder and is relatively low (11.61 years) among those whose mothers do job than those whose mothers are housewives (11.79 years). The girls from families of high socio-economic stratum are better nourished which in turn results in higher BMI that consequently stimulates an early menarche [22]. Socioeconomic status and age at menarche are negatively related in a number of countries [23]. This study also revealed that the socio-economic status is inversely related to mean menarcheal age. The lowest mean menarcheal age is found among the girls belong to high socio-economic stratum (11.40 years).

Students from small-sized families attained menarche earlier than those from larger families [24]. The results of this study (Table 2)also reveal that the mean menarcheal age is found relatively the lowest (11.67 years) among the respondents whose family members are less than or equal to four. The reasons behind the low mean menarcheal age among small families is due to the fact that the girls of these families get enough facilities including food. The mean menarcheal age is the highest (11.77 years) among the respondents who have game habit. The variable 'duration of sleeping habit' is also negatively related to the respondent's menarcheal age. Mean age at menarche is computed as the lowest (11.68 years) who have sleeping habit above 8 hours per day. High nutritious intake is the higher percentage of body fat and the earlier age at menarche $[25,26]$. Findings in the Table 2also show that the mean 
menarcheal age is the lowest (11.38 years) among the respondents who intake rich food.

In addition to descriptive statistics of menarcheal age, we have also constructed abridged life table for having the probability of first menstruation in different age groups considering censored cases. The probabilities by age groups and other summary measures are presented in the Table 4 and Table 5 respectively.

Table 4. Abridged life table for age at menarche among school girls in Chittagong metropolitan area

\begin{tabular}{|c|c|c|c|c|c|c|c|}
\hline 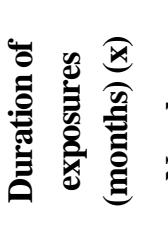 & 离 & 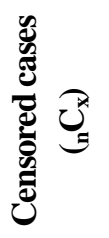 & 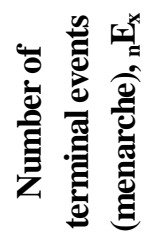 & 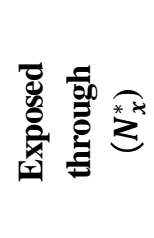 & 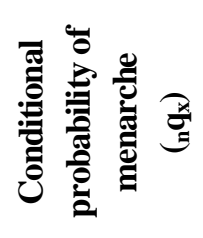 & 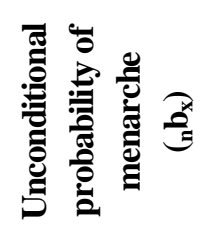 & 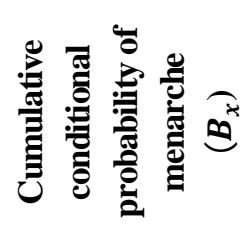 \\
\hline (1) & (2) & (3) & (4) & (5) & (6) & (7) & (8) \\
\hline 104-116 & 922 & 4 & 11 & 918 & 0.012 & 0.012 & 0.012 \\
\hline $116-122$ & 907 & 15 & 28 & 892 & 0.031 & 0.030 & 0.024 \\
\hline $122-128$ & 864 & 26 & 72 & 838 & 0.086 & 0.081 & 0.054 \\
\hline $128-134$ & 766 & 15 & 100 & 751 & 0.133 & 0.115 & 0.135 \\
\hline $134-140$ & 651 & 29 & 176 & 622 & 0.283 & 0.212 & 0.250 \\
\hline $140-146$ & 446 & 19 & 146 & 427 & 0.342 & 0.184 & 0.462 \\
\hline $146-152$ & 281 & 13 & 125 & 268 & 0.466 & 0.165 & 0.646 \\
\hline $152-158$ & 143 & 12 & 63 & 131 & 0.481 & 0.091 & 0.811 \\
\hline $158-164$ & 68 & 11 & 31 & 57 & 0.544 & 0.053 & 0.902 \\
\hline $164-170$ & 26 & 0 & 12 & 26 & 0.462 & 0.021 & 0.955 \\
\hline $170-176$ & 14 & 2 & 7 & 12 & 0.583 & 0.014 & 0.976 \\
\hline $176^{+}$ & 5 & 2 & 3 & 3 & 1 & 0.010 & 0.990 \\
\hline
\end{tabular}

In the Table- $4, B_{170}=0.955$ indicates that about $96 \%$ girls likely to attain menarche within 170 months (14.17 years) of their birth. The findings from the life table 
190 Patterns and Differentials of Onset of Menstruation among School Girls in Chittagong Metropolitan Area of Bangladesh

analysis also reveal that unexpectedly $1.2 \%$ girls likely to attain menarche only within age of 9.67 years $\left(B_{116}=0.012\right)$ and this proportion rises $13.5 \%, 46.2 \%$, $64.6 \%$ and $90.2 \%$ within $11.17,12.17,12.67$ and 13.67 years of their birth respectively.

The quartiles of the menarcheal age are also calculated accordingly by employing linear interpolation technique for understanding the patterns of onset of menstruation in different quarters. Based on the quarters, the trimean is calculated using a general formula, $\mathrm{T}=\frac{\left(Q_{1}+2 Q_{2}+Q_{3}\right)}{4}=140$ months (11.67 years) and the spread is estimated as, $\mathrm{s}=Q_{3}-Q_{1}=16$ months. The computed summary measures of age at menarche are presented in the Table 5 in order to understand patterns of age at menarche by age groups.

Table 5. Summary measures of age at menarche among school girls in Chittagong metropolitan area.

\begin{tabular}{cc}
\hline Summary measures & Age at menarche \\
\hline$B_{116}$ & 0.012 \\
$B_{164}$ & 0.902 \\
$Q_{1}$ & 132 months $(11.00$ years $)$ \\
$Q_{2}=$ Median & 140 months $(11.67$ years $)$ \\
$Q_{3}$ & 148 months $(12.33$ years $)$ \\
Trimean $(\mathrm{T})$ & 140 months $(11.67$ years $)$ \\
Spread (s)= Quartile range & 16 months $(1.33$ years $)$ \\
\hline No. of cases & $922\left(774+148^{*}\right)$ \\
\hline
\end{tabular}

* Figure indicates censored cases

Findings from the Table 5 reflect that median age at menarche is computed as 11.67 years. The trimean of age at first menstruation is also computed as 11.67 years. A petty difference has been observed between overall mean and trimean of 
age at menarche because a small number of girls have not attained onset of menstruation at the time of interview. The value of spread ( $s=16$ months) indicates that there exist extreme heterogeneity of the menarcheal age.

In addition to the findings presented in the Table 4, the cumulative probability by menarcheal age are also depicted in the Fig. 3 for clear understanding of probability of attaining menarche in the different points of exposure duration of menarcheal age.

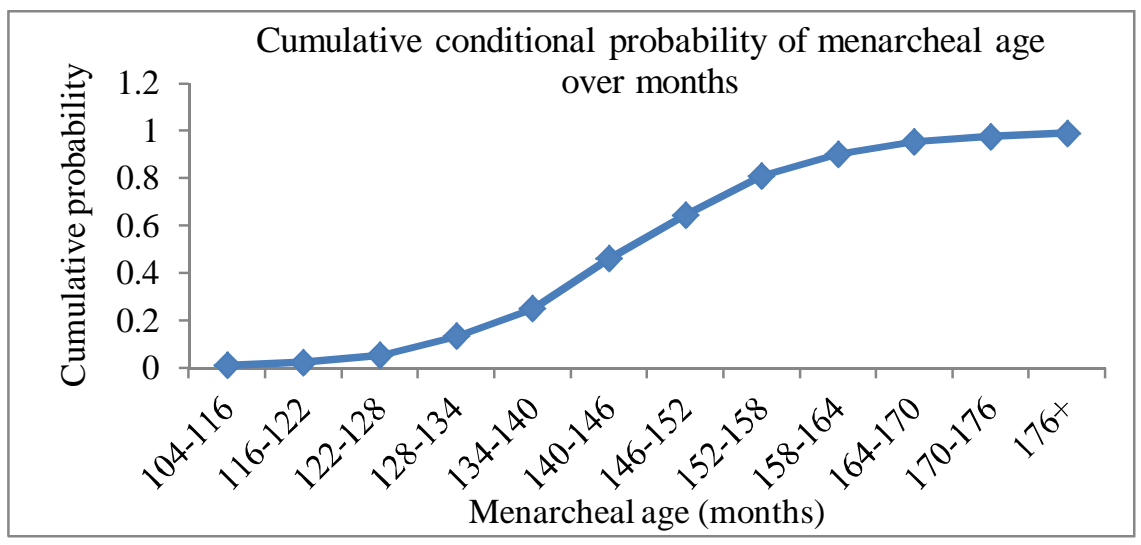

Fig. 3: Life table function of age at menarche.

Fig. 3 reveals that the cumulative proportion of the menarcheal age increases narrowly up to 130 months (10.84 years) then increases shapely up to 170 months (14.17 years). Among the explanatory variables, nutritional status of the respondents is found very important for the variation of puberty because it is well established fact that well nourished girls reached menarche earlier than undernourished girls. Therefore, three abridged life tables for age at menarche are constructed for different categories of nutritional status (BMI) and the probabilities 
192 Patterns and Differentials of Onset of Menstruation among School Girls in Chittagong Metropolitan Area of Bangladesh

by age groups are presented in the Table 6andsummary measures are in the Table 7 . It is observed from the Table 6 that $3.7 \%$ underweight girls likely to attain menarche within 10.67 years after their birth. The findings reveal that 17\%, 56.5\% and $84.3 \%$ girls are likely to attain menarche within ages of $11.67,12.67$ and 13.67 years respectively when censored girls are also considered. Table 6 also shows that $5 \%$ normal weight girls likely to attain menarche only within 10.67 years after their birth.

Table 6. Abridged life table forage at menarche among girls of different body weight in Chittagong metropolitan area

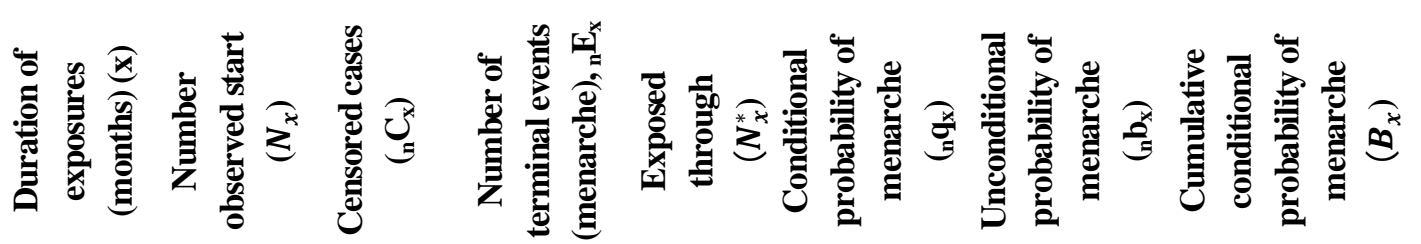

\begin{tabular}{cccccccc}
$(1)$ & $(2)$ & $(3)$ & $(4)$ & $(5)$ & $(6)$ & $(7)$ & $(8)$ \\
\hline \multicolumn{7}{c}{ Underweight } \\
\hline $104-116$ & 356 & 2 & 4 & 354 & 0.011 & 0.011 & 0.011 \\
$116-122$ & 350 & 11 & 5 & 339 & 0.015 & 0.015 & 0.022 \\
$122-128$ & 334 & 15 & 12 & 319 & 0.038 & 0.037 & 0.037 \\
$128-134$ & 307 & 9 & 31 & 298 & 0.104 & 0.096 & 0.074 \\
$134-140$ & 232 & 18 & 57 & 214 & 0.266 & 0.221 & 0.170 \\
$140-146$ & 175 & 10 & 47 & 165 & 0.285 & 0.174 & 0.391 \\
$146-152$ & 125 & 6 & 44 & 119 & 0.370 & 0.161 & 0.565 \\
$152-158$ & 84 & 9 & 32 & 75 & 0.427 & 0.117 & 0.726 \\
\hline $158-164$ & 57 & 7 & 20 & 50 & 0.400 & 0.063 & 0.843 \\
$164-170$ & 50 & 0 & 7 & 50 & 0.140 & 0.013 & 0.906 \\
$170^{+}$ & 40 & 4 & 6 & 36 & 0.167 & 0.013 & 0.919 \\
\hline & & & & & & & Table 6 conti.
\end{tabular}




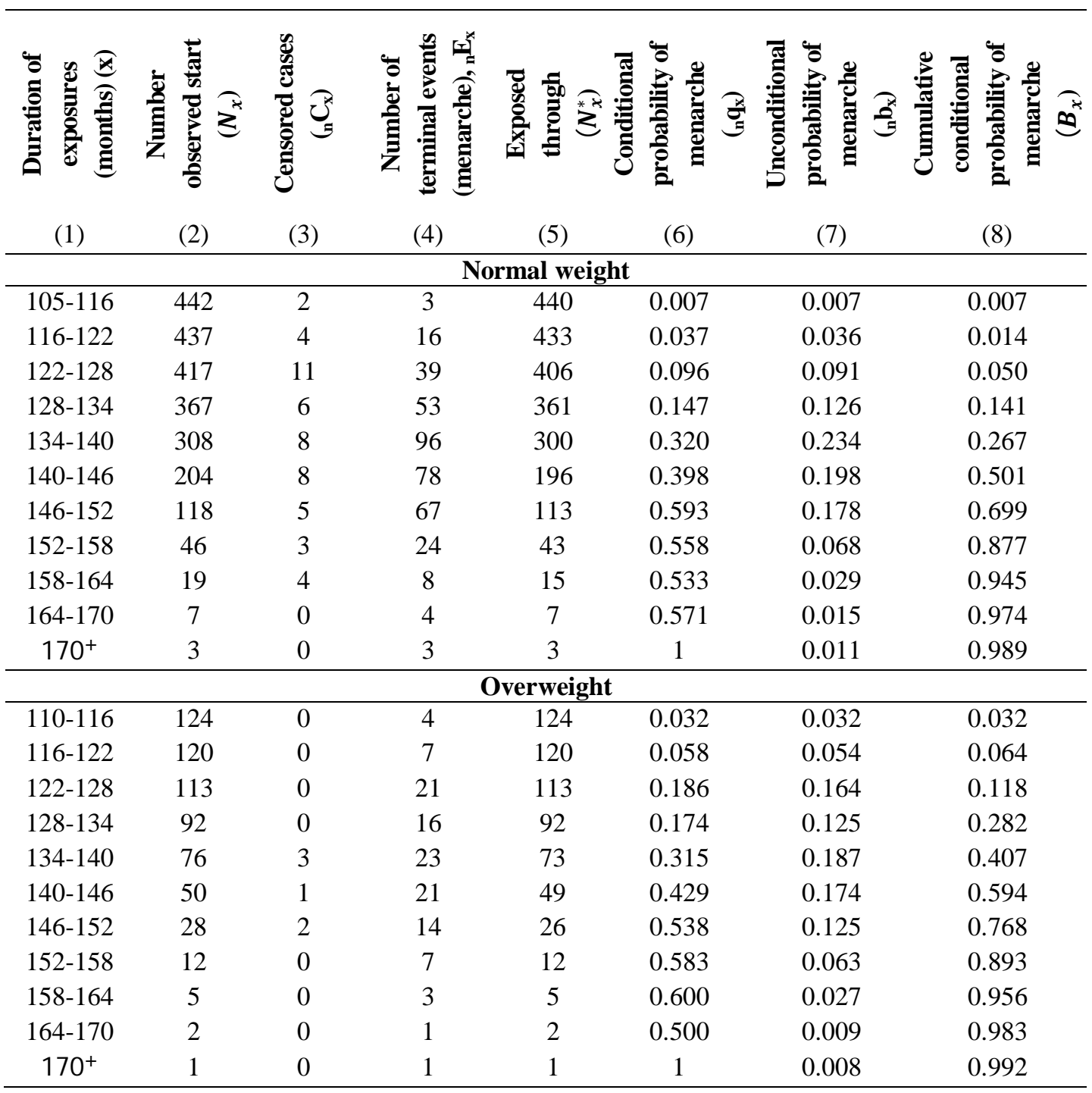

The result further reveals that $94.5 \%$ normal weight girls likely to attain menarche within age of 13.67 years. Findings regarding overweight girls state that expectedly $3.2 \%$ girls likely to attain menarche only within age of 9.67 years and $95.6 \%$ within 
194 Patterns and Differentials of Onset of Menstruation among School Girls in Chittagong Metropolitan Area of Bangladesh

age of 13.67 years.

Table 7. Summary measures for age at menarche among girls of different body weight in Chittagong metropolitan area.

\begin{tabular}{|c|c|}
\hline Summary measures & Age at menarche \\
\hline \multicolumn{2}{|c|}{ Underweight } \\
\hline$B_{116}$ & 0.011 \\
\hline$B_{164}$ & 0.843 \\
\hline$Q_{1}$ & 134 months (11.17 years) \\
\hline$Q_{2}=$ Median & 141 months (11.75 years) \\
\hline$Q_{3}$ & 152 months (12.67 years) \\
\hline Trimean $(\mathrm{T})$ & 142 months (11.83 years) \\
\hline Spread $(s)=$ Quartile range & 18 months \\
\hline \multicolumn{2}{|c|}{ Normal weight } \\
\hline$B_{116}$ & 0.007 \\
\hline$B_{164}$ & 0.945 \\
\hline$Q_{1}$ & 132 months ( 11.00 years) \\
\hline$Q_{2}=$ Median & 139 months (11.58 years) \\
\hline$Q_{3}$ & 147 months ( 12.25 years) \\
\hline Trimean $(\mathrm{T})$ & 139 months (11.58 years) \\
\hline Spread $(s)=$ Quartile range & 15 months \\
\hline \multicolumn{2}{|c|}{ Overweight } \\
\hline$B_{116}$ & 0.032 \\
\hline$B_{164}$ & 0.956 \\
\hline$Q_{1}$ & 128 months (10.67 years) \\
\hline$Q_{2}=$ Median & 137 months (11.41 years) \\
\hline$Q_{3}$ & 145 months (12.08 years) \\
\hline Trimean $(\mathrm{T})$ & 137 months (11.41 years) \\
\hline Spread $(s)=$ Quartile range & 17 months \\
\hline
\end{tabular}

Summary measures from the Table 7 show that trimean of menarcheal age is 11.83 years for underweight girls. The value of spread of menarcheal age for underweight girls is calculated as 18 months, which is also 2 months higher than the spread for overall girls. The value of spread indicates the extreme heterogeneity of the menarcheal age for underweight girls. In case of normal weight girls, the trimean of menarcheal age is found 11.58 years, which is 0.09 year lower than the trimean 
( $\mathrm{T}=11.67$ years) of all girls. The result of spread illustrates that variability of age at menarche is found relatively lower among normal weight girls. The trimean of menarcheal age among overweight girls is found 11.41 years. The value of spread of menarcheal age ( $\mathrm{s}=17$ months) indicates that there also exists extreme heterogeneity of the menarcheal age among overweight girls compared to normal weight girls. The comparative figures of spread among three categories of BMI illustrate that the spreads are higher both underweight and overweight girls.

Besides the findings presented in the Table 6, the cumulative probability by age at first menstruation of the girls for different categories of nutritional status are also depicted in the Fig. 4.

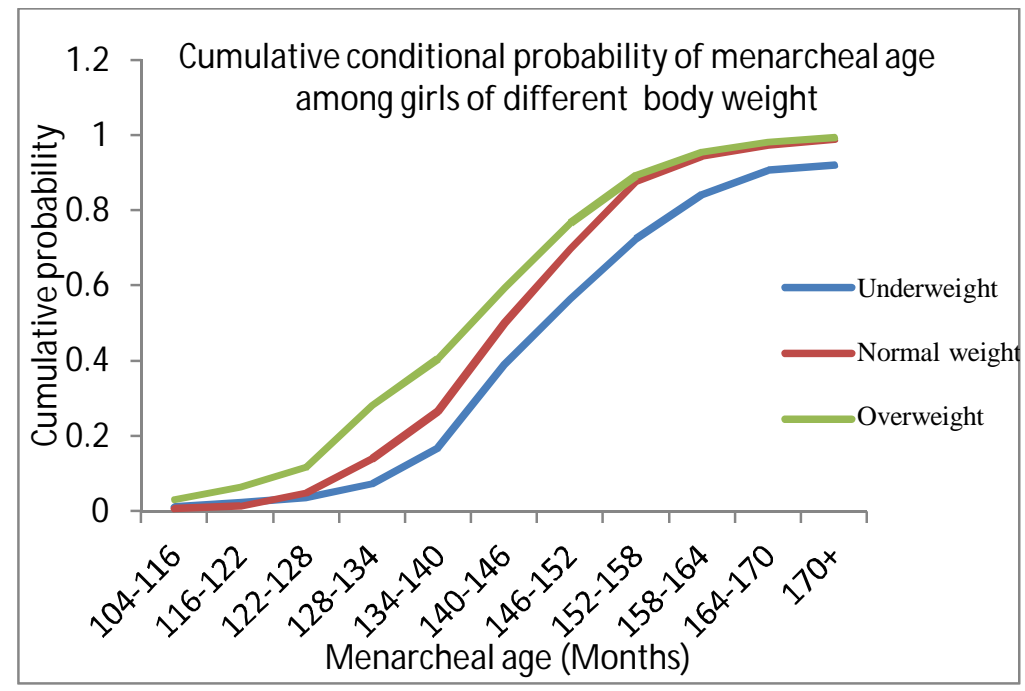

Fig. 4: Life table function of menarcheal age among girls of different body weight.

It is observed from the Fig. 4 that the cumulative proportion of the age at menarche among underweight girls increases narrowly up to 134 months (11.17 years) then 
196 Patterns and Differentials of Onset of Menstruation among School Girls in Chittagong Metropolitan Area of Bangladesh

increases sharply up to 170 months. Furthermore, the cumulative proportion of attaining menarche among normal weight girls steadily increases up to 128 months. The cumulative proportion of the age at menarche among overweight girls' increases narrowly up to 122 months; subsequently, increases sharply up to 164 months. Moreover, the values of trimean and cumulative proportions show that overweight

girls take relatively less time of attaining menarche. Nonetheless, girls belong to underweight stratum take relatively longer time period to attain menarche. The findings at a glance reflect that age at menarche is associated with girl's nutritional status.

\section{Conclusions}

Although onset of menstruation is a biological and physiological process but its onset profoundly changes a young woman's life. Undoubtedly the most striking event in the whole process of female puberty is the onset of menstruation [27]. It is now becoming recognized that the earlier onset of menstruation has been observed in some developing countries. In this study, the mean age at menarche of the randomly selected girls was found only 11.75 years. Differentials by background characteristics show that place of residence have wide variations of first menstruations because the residential heterogeneity among the respondents in respect to socio-economic conditions is obvious. In urban areas, the father's education is associated with an earlier menarche of girls [28]. Girls attain later menarche in lower socio-economic group as they do not get adequate privilege to lead their life. The mean age at first menstruation is found relatively lower among the overweight compared to underweight girls $(11.43 ; 12.01$ years).The findings reflect that nutritional status has 
substantial impact on age at menarche. The lowest age at menarche has been computed among the girls who have small family size because respondents of this category have access to adequate food supplies, use of health service and sanitation facilities. The mean age at menarche is found the lowest among the respondents who intake rich food. That means excessive intake of rich food should be avoided to reduce the too early menarche among school girls. Life table analysis reveals that $1.2 \%$ girls likely to attain menarche within only age of 9.67 years. Findings from the life table technique also reflect that overweight respondents take relatively less time to attain menarche compared to those who belong to underweight stratum. Thus, it can be concluded that balanced nutritional status of girls likely to be helpful for natural timing of menarche. Moreover, natural age onset of menstruation may be helpful to reduce absenteeism in the school, risk of breast cancer and other chronic diseases. Therefore, inclusion of mothers in this important physiological process may serve to enhance the mental and psychological development of their girls at the time of occurrence of this vital episode.

\section{References}

[1] L. Barclay: Austrian Family Physician, 1982, 11(6), 452.

[2] T. Adali and I. Koc: Annals of Human Biology, 2011, 38(3), 345.

[3] P. Kaplowitz: Current Opinion in Obstetrics and Gynecology, 2006, 18(5), 487.

[4] M. E. Herman-Giddens: Journal of Adolescent Health, 2007, 40(3), 201.

[5] J. L. Kelsey: Epidemiologic Reviews, 1979, 1, 74.

[6] E. B. Greif and K. J. Ulman: Child Development, 1982, 1413.

[7] M. C. Jones and P. H. Mussen: Child Development, 1958, 491. 
198 Patterns and Differentials of Onset of Menstruation among School Girls in Chittagong Metropolitan Area of Bangladesh

[8] I. Wronka: AnthropologischerAnzeiger, 2010, 68(1), 43.

[9] J. L. Kelsey and L. Bernstein: Annual Review of Public Health, 1996, 17(1), 47.

[10] J. L. Kelsey, M. D. Gammon and E. M. John: Epidemiologic Reviews, 1993, 15(1), 36.

[11] L. A. Mucci, H. E. Kuper, R. Tamimi, P. Lagiou, E. Spanos and D. Trichopoulos: An International Journal of Obstetrics and Gynaecology, 2001, 108(3), 291.

[12] T. Johansson and E. M. Ritzen: Abnormalities in Puberty, 2005, 8, 126.

[13] R. Lakshman, N. G. Forouhi, S. J. Sharp, R. Luben, S. A. Bingham, K. T. Khaw and K. K. Ong: The Journal of Clinical Endocrinology and Metabolism, 2009, 94(12), 4953.

[14] W. Wisemandle, L. M. Maynard, S. S. Guo and R. M. Siervogel: Pediatrics, 2000, 106(1), 14.

[15] S. Arslanian: Clinical Pediatrics, 1998, 37(2), 81.

[16] P. Riley, J. L. Samuelson and S. L. Huffman: Biomedical Determinants of Reproduction, 1993, 50.

[17] S. S. Guo, W. C. Chumlea, A. F. Roche and R. M. Siervogel: International Journal of Obesity, 1997, 21(12), 1167.

[18] F. Macsali, F. G. Real, E. Plana, J. Sunyer, J. Anto, J. Dratva and M. Wjst: American Journal of Respiratory and Critical Care Medicine, 2011, 183(1), 8.

[19] M. Rees: Orgyn, 1995, (4), 2.

[20] M. G. Hossain, S. Islam, S. Aik, T. K. Zaman and P. E. Lestrel: Journal of Biosocial Science, 2010, 42(5), 677. 
[21] A. Chowdhury, S. L. Huffman and G. T. Curlin: Social Biology, 1977, 24(4), 316.

[22] S. Berkey, J. D. Gardner, A. L. Frazier and G. A. Colditz: American Journal of Epidemiology, 2000, 152(5), 446.

[23] J. Bongaarts: Studies in Family Planning, 1980, 11(12), 401.

[24] M. G. Hossain,A. S. Wee,M. Ashaie and T. Kamarul: Journal of Biosocial Science, 2013,45(5), 705.

[25] K. Edmonds: "Dewhurst's Textbook of Obstetrics and Gynaecology for Postgraduates", 1999.

[26] J. Laitinen, C. Power and M. R. Jarvelin :The American Journal of Clinical Nutrition, 2001,74(3), 287.

[27] P. B. Eveleth and J. M. Tanner: "Worldwide Variation in Human Growth", 1976.

[28] I. Wronka and R. Pawlińska-Chmara: Annals of Human Biology, 2005, 32(5), 630 .

Manuscript received on 27 August, 2019, Revised manuscript received on 03 December, 2019 and accepted on 29 December, 2019

The Chittagong Univ. J. Sc. Vol. 41(1), 2019 